\title{
Selectivity of Microbial Acyl-CoA : cholesterol Acyltransferase Inhibitors toward Isozymes
}

\author{
Taichi Ohshiro, Lawrence L. Rudel, Satoshi Ōmura, Hiroshi Tomoda
}

Received: September 12, 2006 / Accepted: December 21, 2006

(C) Japan Antibiotics Research Association

\begin{abstract}
The selectivity of microbial inhibitors of acylCoA : cholesterol acyltransferase (ACAT) toward the two isozymes, ACAT1 and ACAT2, was assessed in cell-based assays. Purpactin A ( $\mathrm{IC}_{50}$ values of ACAT1 vs. $\mathrm{IC}_{50}$ values of ACAT2; $2.5 \mu \mathrm{M} v s .1 .5 \mu \mathrm{M})$, terpendole $\mathrm{C}(10 \mu \mathrm{M} v s$. $10 \mu \mathrm{M})$, glisoprenin A $(4.3 \mu \mathrm{M} v s .10 \mu \mathrm{M})$, spylidone $(25 \mu \mathrm{M} v s .5 .0 \mu \mathrm{M})$ and synthetic CL-283,546 $(0.1 \mu \mathrm{M} v s$. $0.09 \mu \mathrm{M})$ inhibited ACAT1 and ACAT2 to similar extents. Beauveriolides I $(0.6 \mu \mathrm{M} v s .20 \mu \mathrm{M})$ and III $(0.9 \mu \mathrm{M} v s$. $>20 \mu \mathrm{M})$ inhibited ACAT1 rather selectively, while pyripyropenes A $(>80 \mu \mathrm{M} v s .0 .07 \mu \mathrm{M})$, B (48 $\mu \mathrm{M} v s$. $2.0 \mu \mathrm{M}), \mathrm{C}(32 \mu \mathrm{M} v s .0 .36 \mu \mathrm{M})$ and $\mathrm{D}(38 \mu \mathrm{M} v s .1 .5 \mu \mathrm{M})$ showed selective inhibition against ACAT2. In particular, pyripyropene A was found to be the most selective ACAT2 inhibitor with a selective index of more than 1,000.
\end{abstract}

Keywords acyl-CoA : cholesterol acyltransferase, isozyme, microbial inhibitors, lipid droplet accumulation, pyripyropene, beauveriolide, atherosclerosis

\section{Introduction}

Acyl-CoA : cholesterol acyltransferase (ACAT), an ER membrane protein, is responsible for many functions in the body. ACAT has been recognized as a target for inhibition by a new type of antiatherosclerotic agents [1]. Many pharmaceutical laboratories have developed synthetic
ACAT inhibitors. However, almost none of them could be successfully developed because of side effects or low in vivo efficacy [2]. Recent molecular biological studies revealed the existence in mammals of two different ACAT isozymes, ACAT1 and ACAT2 [3 6]. ACAT1 is ubiquitously expressed in tissues and cells, while ACAT2 is expressed predominantly in the liver (hepatocytes) and intestine [7]. Therefore, it is important to determine the selectivity of inhibitors toward the two ACAT isozymes for their development as new antiatherosclerotic agents [8]. However, such data have rarely been reported so far $[9,10]$.

Our research group discovered a number of microbial ACAT inhibitors with an enzyme assay using rat liver microsomes; these inhibitors included pyripyropenes [11 13], purpactins [14, 15], glisoprenins [16 18] and terpendoles [19 21] (Fig. 1). The activities of these inhibitors in cell-based assays and their selectivity toward the two ACAT isozymes have not been fully studied. We also developed a cell-based assay of lipid droplet accumulation in mouse macrophages, and discovered beauveriolides [22 25], phenochalasins [26, 27], spylidone [28], sespendole [29] and K97-0239s [30] with this assay (Fig. 2). We studied the molecular targets of beauveriolides I and III in macrophages and found that they inhibited cholesteryl ester (CE) synthesis by blocking ACAT activity in macrophages, leading to the inhibition of lipid droplet accumulation. More importantly, they proved orally active in atherogenic mouse models and are expected to provide
H. Tomoda (Corresponding author): School of Pharmacy, Kitasato University, 5-9-1 Shirokane, Minato-ku, Tokyo 1088641, Japan, E-mail: tomodah@pharm.kitasato-u.ac.jp

T. Ohshiro, S. Ōmura: Kitasato Institute for Life Sciences and Graduate School of Infection Control Sciences, Kitasato University, 5-9-1 Shirokane, Minato-ku, Tokyo 108-8641, Japan
L. L. Rudel: Atherosclerosis Research Program, Wake Forest University School of Medicine, Winston-Salem, NC, 27157, USA 


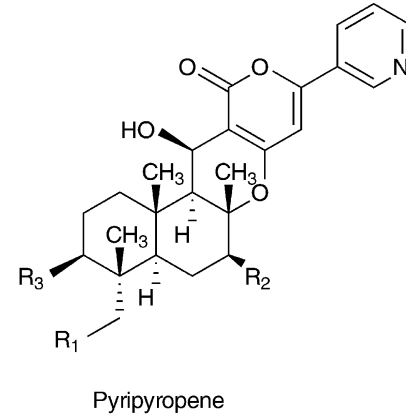

\begin{tabular}{cccc}
\hline Pyripyropene & $\mathrm{R}_{1}$ & $\mathrm{R}_{2}$ & $\mathrm{R}_{3}$ \\
\hline $\mathrm{A}$ & $-\mathrm{OCOCH}_{3}$ & $-\mathrm{OCOCH}_{3}$ & $-\mathrm{OCOCH}_{3}$ \\
B & $-\mathrm{OCOCH}_{2} \mathrm{CH}_{3}$ & $-\mathrm{OCOCH}_{3}$ & $-\mathrm{OCOCH}_{3}$ \\
$\mathrm{C}$ & $-\mathrm{OCOCH}_{3}$ & $-\mathrm{OCOCH}_{2} \mathrm{CH}_{3}$ & $-\mathrm{OCOCH}_{3}$ \\
D & $-\mathrm{OCOCH}_{3}$ & $-\mathrm{OCOCH}_{3}$ & $-\mathrm{OCOCH}_{2} \mathrm{CH}_{3}$ \\
\hline
\end{tabular}

Pyripyropene<smiles>COc1c([C@@H](CC(C)C)OC(C)=O)ccc2c1C(=O)OCc1cc(C)cc(O)c1O2</smiles>

Purpactin A<smiles>COc1c(C(CC(C)C)OC(C)=O)ccc2c1C(=O)C1(O2)C(=O)C=C(C)C=C1C</smiles>

Purpactin B<smiles>COC(=O)C(CC(C)C)c1ccc2c(c1OC)C(=O)C1(O2)C(=O)C=C(C)C=C1C</smiles>

Purpactin C<smiles>CC(C)=CCC[C@](C)(O)CCC[C@](C)(O)CCC[C@](C)(O)CCC[C@](C)(O)CCC/C(C)=C/CC/C(C)=C/CC/C(C)=C/CC/C(C)=C/CO</smiles>

Glisoprenin A

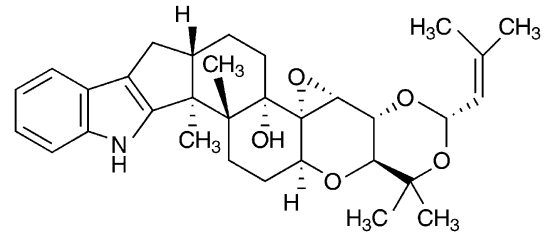

Terpendole C<smiles>CC(C)C(OC(=O)[C@H](Cc1ccccc1)N(C)C(=O)[C@H](Cc1ccccc1)N(C)C(=O)[C@H](Cc1ccccc1)N(C)C(=O)[C@H](Cc1ccccc1)OC(=O)[C@H](Cc1ccccc1)C(C)C)C(C)C</smiles>

Beauvericin

Fig. 1 Structures of acyl-CoA: cholesterol acyltransferase (ACAT) inhibitors discovered using rat liver microsomes in an enzyme-based assay.

a new method for the prevention and treatment of atherosclerosis [31, 32]. However, the molecular targets of the other inhibitors are not yet well defined, and their effect on ACAT activity as a potential target should be studied.

Thus, we studied microbial inhibitors discovered by screening against ACAT (Fig. 1) and lipid droplet accumulation (Fig. 2) by examining their inhibitory activity against ACAT1 and ACAT2 isozymes, and their selectivity toward the isozymes. For the examination, two cell lines, CHO cells expressing African Green monkey ACAT1 (ACAT1-CHO) and ACAT2 (ACAT2-CHO) were used [9].

\section{Materials and Methods}

\section{Materials}

Pyripyropenes A to D [11 13], purpactins A to C [14, 15], glisoprenin A [16 18], terpendole C [19 21], beauveriolides I and III [22 25], phenochalasin A [26, 27], spylidone [28], sespendole [29] and K97-0239A and B [30] were purified from the culture broth of the respective producing microorganism according to the established methods. CL-283,546, a synthetic ACAT inhibitor, was a generous gift from J. Hess (Pfizer, USA). $\left[1-{ }^{14} \mathrm{C}\right]$ Oleic acid 


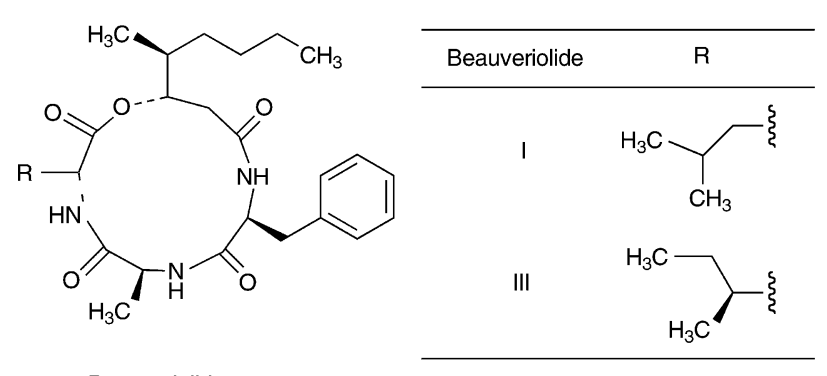

Beauveriolide<smiles>CC1=CC(/C=C/CC(C)C(=O)C(C)(C)O)C2(OC(=O)O/C=C\C1C)C(=O)NC(Cc1ccc(O)cc1)C2C</smiles>

Phenochalasin A

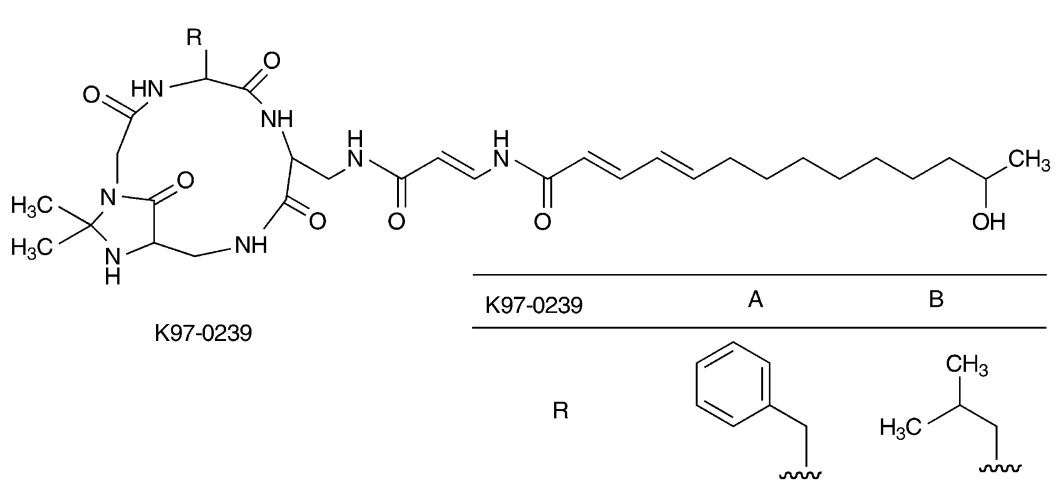<smiles>CCC(C)C1N(C)C(=O)C2(C(=O)C3(C)C(=O)C4C5C(C)CC(C)CC5C=CC4C(O)(O)C3C)C(=O)C12C</smiles>

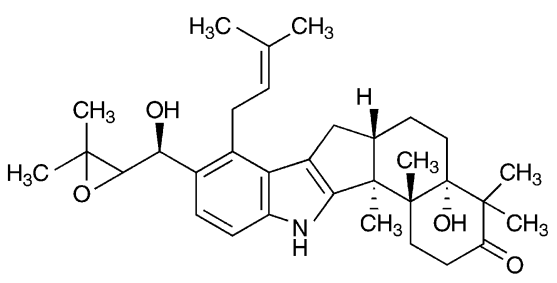

Sespendole$$
\text { ns }
$$

Fig. 2 Structures of inhibitors of lipid droplet accumulation discovered using mouse macrophages in a cell-based assay.

was purchased from PerkinElmer Life and Analytical Sciences (USA). $\left[1-{ }^{14} \mathrm{C}\right]$ Oleoyl-coenzyme A was purchased from GE Healthcare Bio-Sciences (USA). Dulbecco's modified Eagle's medium (DMEM) and Hank's buffered salt solution (HBSS) were purchased from Nissui Pharmaceutical (Japan). GIT medium was from Nihon Pharmaceutical. Fetal bovine serum (FBS) was from HyClone (USA). HAM's F12, phosphatidylcholine, phosphatidylserine, diacetylphosphate, cholesterol, and fatty acid-free bovine serum albumin (BSA) were obtained from Sigma-Aldrich (USA). Geneticin (G-418 sulfate) and MEM vitamin solution were from Wako Pure Chemical Industries (Japan). Penicillin (10,000 units/ml)/ streptomycin $(10,000 \mathrm{mg} / \mathrm{ml})$ and L-glutamine $(200 \mathrm{mM})$ solution were from Invitrogen (USA). Plastic microplates (48-well) were purchased from Asahi Techno Glass (Japan). Tissue culture chambers were purchased from Nalge Nunc International (USA).

\section{Assay for Lipid Droplet Accumulation in Macrophages}

The morphological assay for lipid droplet accumulation in mouse peritoneal macrophages was carried out according to the method described previously [33]. Briefly, primary mouse peritoneal macrophages $\left(4 \times 10^{5}\right.$ cells in GIT medium) in each well of a tissue culture chamber were incubated in a humidified $\mathrm{CO}_{2}(5 \% \mathrm{v} / \mathrm{v})$ incubator at $37^{\circ} \mathrm{C}$ for 2 hours. The medium was then replaced with $0.2 \mathrm{ml}$ of DMEM containing 7\% (v/v) lipoprotein-deficient serum (LPDS), penicillin (100 units/ml) and streptomycin $(100 \mathrm{mg} / \mathrm{ml})$ (hereafter referred to as medium A). After a 2-hours preincubation, $2.0 \mu \mathrm{l}$ of a sample in methanol, and $8.0 \mu \mathrm{l}$ of liposomes (phosphatidylcholine $1.0 \mu \mathrm{mol}$, phosphatidylserine $1.0 \mu \mathrm{mol}$, dicetylphosphate $0.2 \mu \mathrm{mol}$ and cholesterol $1.5 \mu \mathrm{mol}$, suspended in $1.0 \mathrm{ml}$ of $0.3 \mathrm{M}$ glucose) were added to each well. After a 14-hours incubation, the cells were washed with PBS and then fixed by soaking in $10 \%$ formalin. Nuclei and intracellular 
neutral lipid droplets were then stained with hematoxylin and oil red $\mathrm{O}$, respectively. The lipid droplet accumulation and morphological changes in macrophages were examined by light microscopy (Vanox-S model, Olympus).

\section{Assay for Neutral Lipid Synthesis in Macrophages}

The assay for the synthesis of $\left[{ }^{14} \mathrm{C}\right] \mathrm{CE}$ and $\left[{ }^{14} \mathrm{C}\right]$ triacylglycerol (TG) synthesis from $\left[{ }^{14} \mathrm{C}\right]$ oleic acid in mouse peritoneal macrophages was carried out by our established method [33]. Briefly, mouse peritoneal macrophages $\left(5 \times 10^{5}\right.$ cells in $250 \mu \mathrm{l}$ of medium A) were cultured in each well of a 48 -well plastic microplate, and then $2.5 \mu \mathrm{l}$ of a test compound (methanol solution) and $10 \mu \mathrm{l}$ of liposomes together with $5 \mu$ of $\left[1-{ }^{14} \mathrm{C}\right]$ oleic acid $(1 \mathrm{nmol}, 1.85 \mathrm{KBq}$, $10 \%$ ethanol/PBS solution) were added to each culture at $37^{\circ} \mathrm{C}$ in $5 \% \mathrm{CO}_{2}$. Following a 14-hours incubation, the medium was removed, and the cells in each well were washed twice with PBS. The cells were lysed by adding $0.25 \mathrm{ml}$ of $10 \mathrm{mM}$ Tris- $\mathrm{HCl}(\mathrm{pH} 7.5)$ containing $0.1 \%(\mathrm{w} / \mathrm{v})$ sodium dodecyl sulfate (SDS), and the cellular lipids were extracted by the method of Bligh and Dyer [34]. After the organic phase was concentrated, the total lipids were separated on a TLC plate (silica gel F254, $0.5 \mathrm{~mm}$ thick, Merck, Germany) and analyzed with a bioimaging analyzer (BAS 2000, Fuji Film, Japan).

\section{Culture of ACAT1- and ACAT2-CHO Cells}

ACAT1-CHO and ACAT2-CHO cells were cultured by the method described previously [9]. Briefly, both cell lines were maintained at $37^{\circ} \mathrm{C}$ in $5 \% \mathrm{CO}_{2}$ in Ham's $\mathrm{F}-12$ medium supplemented with MEM vitamins, geneticin $(300 \mu \mathrm{g} / \mathrm{ml})$ and $10 \%$ heat inactivated FBS (hereafter referred to as medium B).

\section{Assay for $\left[{ }^{14} \mathrm{C}\right] \mathrm{CE}$ Synthesis in ACAT1- or ACAT2- CHO Cells}

ACAT1- or ACAT2-CHO cells $\left(1.25 \times 10^{5}\right.$ cells in $250 \mu \mathrm{l}$ of medium B) were cultured in a 48 -well plastic microplate and allowed to recover overnight at $37^{\circ} \mathrm{C}$ in $5 \% \mathrm{CO}_{2}$. The assays were done with cells that were at least $80 \%$ confluent. Following the overnight recovery, $2.5 \mu 1$ of a sample (methanol solution) and $5 \mu \mathrm{l}$ of $\left[1-{ }^{14} \mathrm{C}\right]$ oleic acid $(1 \mathrm{nmol}, 1.85 \mathrm{KBq}, 10 \%$ ethanol/PBS solution) were added to each culture at $37^{\circ} \mathrm{C}$ in $5 \% \mathrm{CO}_{2}$. After a 6-hours incubation, the medium was removed, and the cells in each well were washed twice with PBS. The cells were lysed by adding $0.25 \mathrm{ml}$ of $10 \mathrm{mM}$ Tris- $\mathrm{HCl}(\mathrm{pH} 7.5)$ containing $0.1 \%(\mathrm{w} / \mathrm{v}) \mathrm{SDS}$, and $\left[{ }^{14} \mathrm{C}\right] \mathrm{CE}$ and $\left[{ }^{14} \mathrm{C}\right] \mathrm{TG}$ were analyzed by the same method described above. In this cell-based assay, $\left[{ }^{14} \mathrm{C}\right] \mathrm{CE}$ was produced by the reaction of ACAT1 or ACAT2. ACAT inhibitory activity (\%) is defined as $\left(1-\left[{ }^{14} \mathrm{C}\right] \mathrm{CE}\right.$-drug/ $\left[{ }^{14} \mathrm{C}\right] \mathrm{CE}$-control $) \times 100$. The $\mathrm{IC}_{50}$ value is defined as the drug concentration causing $50 \%$ inhibition of an enzyme (or biological) activity.

\section{Preparation of Microsomes from ACAT1- or ACAT2- CHO Cells}

ACAT1- or ACAT2-CHO cells $\left(2 \times 10^{8}\right.$ cells $)$ were homogenized in $10 \mathrm{ml}$ of cold buffered sucrose solution (pH 7.2) containing $100 \mathrm{mM}$ sucrose, $50 \mathrm{mM} \mathrm{KCl}, 40 \mathrm{mM}$ $\mathrm{KH}_{2} \mathrm{PO}_{4}$ and $30 \mathrm{mM}$ EDTA (hereafter referred to as buffer A) in a Teflon homogenizer. The microsomal fraction was pelleted by centrifugation at $100,000 \times g$ for 1 hour at $4^{\circ} \mathrm{C}$, resuspended in the same buffer at a concentration of $5 \mathrm{mg}$ protein $/ \mathrm{ml}$ and stored at $-80^{\circ} \mathrm{C}$ until use.

\section{Assay for ACAT Isozyme Activity in Microsomes}

ACAT1 and ACAT2 activities were determined by using microsomes prepared as described above as the enzyme source [35]. Briefly, an assay mixture containing $2.5 \mathrm{mg} / \mathrm{ml}$ BSA in buffer A and $\left[1{ }^{14} \mathrm{C}\right]$ oleoyl-CoA $(20 \mu \mathrm{M}, 3.7 \mathrm{kBq})$ together with a test sample (added as a $10 \mu 1$ methanol solution), and the ACAT1 or ACAT2 microsomal fraction (150 or $10 \mu \mathrm{g}$ of protein, respectively) in a total volume of $200 \mu 1$ were incubated at $37^{\circ} \mathrm{C}$ for 5 minutes. The reaction was started by adding $\left[1-{ }^{14} \mathrm{C}\right]$ oleoyl-CoA, and stopped by adding $1.2 \mathrm{ml}$ of $\mathrm{CHCl}_{3}: \mathrm{MeOH}(2: 1)$. The product $\left[{ }^{14} \mathrm{C}\right] \mathrm{CE}$ was extracted by the method of Bligh and Dyer [34]. After the organic solvent was removed by evaporation, lipids was separated on a TLC plate and the radioactivity of $\left[{ }^{14} \mathrm{C}\right] \mathrm{CE}$ was measured as described above.

\section{Results}

\section{Inhibition of Lipid Droplet Accumulation and CE Synthesis in Macrophages}

Microbial ACAT inhibitors previously discovered in an enzyme assay using rat liver microsomes (Fig. 1) were evaluated in assays for lipid droplet accumulation in macrophages. In this morphological assay, purpactins, glisoprenin A and terpendole $\mathrm{C}$ were found to inhibit lipid droplet accumulation in macrophages at $20 \mu \mathrm{M}$ (data not shown). In the biochemical assay, they selectively inhibited $\mathrm{CE}$ synthesis in macrophages more than TG synthesis (Table 1). Thus, purpactins, glisoprenin A and terpendole C inhibited CE synthesis because of blockage of ACAT activity in macrophages. On the other hand, pyripyropenes showed almost no effect on lipid droplet accumulation in macrophages even at $20 \mu \mathrm{M}$. Furthermore, pyripyropene A did not inhibit $\mathrm{CE}$ synthesis in macrophages, and the other pyripyropenes (B to D) showed extremely weak activity 
Table 1 Effect of microbial inhibitors on cholesteryl ester (CE) and triacylglycerol (TG) synthesis in macrophages

\begin{tabular}{|c|c|c|c|c|}
\hline \multirow{2}{*}{ Compound } & \multirow{2}{*}{$\begin{array}{c}\text { Assay system in } \\
\text { which discovered* }\end{array}$} & \multicolumn{2}{|c|}{$I_{50}(\mu \mathrm{M})$} & \multirow{2}{*}{ Ref. } \\
\hline & & CE synthesis & TG synthesis & \\
\hline Pyripyropene A & A & $>80$ & $>80$ & this study \\
\hline Pyripyropene B & $A$ & 38 & $>80$ & $"$ \\
\hline Pyripyropene C & A & 40 & $>80$ & $"$ \\
\hline Pyripyropene D & $A$ & 35 & $>80$ & $"$ \\
\hline Purpactin A & A & 4.5 & $>25$ & $"$ \\
\hline Purpactin B & A & 20 & $>25$ & $"$ \\
\hline Purpactin C & A & 18 & $>25$ & $"$ \\
\hline Glisoprenin A & A & 12 & $>15$ & $"$ \\
\hline Terpendole C & $A$ & 2.5 & $>20$ & $"$ \\
\hline Beauvericin & A & 0.13 & 0.35 & $"$ \\
\hline Beauveriolide I & $\mathrm{B}$ & 0.78 & $>20$ & {$[22,23]$} \\
\hline Beauveriolide III & B & 0.41 & $>20$ & \\
\hline Phenochalasin A & $B$ & 0.6 & $>20$ & {$[26,27]$} \\
\hline Spylidone & B & 42 & $>100$ & [28] \\
\hline Sespendole & B & 4.0 & 3.2 & [29] \\
\hline K97-0239A & B & 1.5 & $50 \%$ at $15 \mu \mathrm{M}$ & [30] \\
\hline K97-0239B & B & 1.7 & $30 \%$ at $15 \mu \mathrm{M}$ & \\
\hline CL-283,546 & - & 0.035 & $>0.1$ & [31] \\
\hline
\end{tabular}

* Assay system; (A) acyl-CoA : cholesterol acyltransferase (ACAT) activity in rat liver microsomes, (B) lipid droplet accumulation in mouse macrophages. The data are expressed as the mean $(N=5)$.

against $\mathrm{CE}$ synthesis, although they are the most potent ACAT inhibitors (with $\mathrm{nM}$ levels of $\mathrm{IC}_{50}$ values) in rat liver microsomes. Beauvericin inhibited the synthesis of both $\mathrm{CE}$ and TG because of its cytotoxic effect on macrophages ( $\mathrm{IC}_{50} 0.9 \mu \mathrm{M}$, data not shown). Synthetic urea CL-283,546 showed the most potent inhibition of CE synthesis $\left(\mathrm{IC}_{50}\right.$ $0.035 \mu \mathrm{M})$ in macrophages among the ACAT inhibitors shown in Fig. 1.

\section{Selectivity of Microbial Inhibitors toward ACAT Isozymes}

1) Cell-based Assay Using ACAT1- and ACAT2-CHO Cells

Microbial inhibitors of lipid metabolism were evaluated in the cell-based assay to quantify $\left[{ }^{14} \mathrm{C}\right] \mathrm{CE}$ catalyzed by ACAT1 and ACAT2 in the respective CHO cells, and the $\mathrm{IC}_{50}$ values are summarized in Table 2. Pyripyropenes were found to selectively inhibit ACAT2 activity. In particular, pyripyropene A was active only against ACAT2, with a selectivity index (SI) of $>1,000$, followed by pyripyropene C. Thus, pyripyropene A was confirmed to be the most selective ACAT2 inhibitor [9, 36]. Purpactins, glisoprenin $\mathrm{A}$, terpendole $\mathrm{C}$, beauvericin, spylidone, sespendole and CL-283,546 inhibited both ACAT1 and ACAT2 activities with SI values of 1.0 to 5.0. On the other hand, beauveriolides I and III selectively inhibited ACAT1 activity with SI values of 33 and $>22$, respectively. However, phenochalasin A, K97-0239A and B showed no or very weak activity against ACAT1 and ACAT2 as compared with their $\mathrm{IC}_{50}$ values of $\mathrm{CE}$ synthesis $(0.6,1.5$ and $1.7 \mu \mathrm{M}$, respectively $[26,27,30])$ in the macrophage assay, indicating that their molecular targets in macrophages are not ACAT.

2) Enzyme Assay Using Microsomes from ACAT1- and ACAT2-CHO Cells

The $\mathrm{IC}_{50}$ values of microbial inhibitors in ACAT assays using microsomes prepared from ACAT1- and ACAT2$\mathrm{CHO}$ cells are summarized in Table 2 . The $\mathrm{IC}_{50}$ values in the enzyme assay generally showed good agreement with those in the cell-based assay using ACAT1- and ACAT2$\mathrm{CHO}$ cells. However, beauveriolides I and III were found to 
Table 2 Selectivity of microbial inhibitors toward acyl-CoA: cholesterol acyltransferase (ACAT) isozymes

\begin{tabular}{|c|c|c|c|c|c|c|}
\hline \multirow{3}{*}{ Compound } & \multicolumn{6}{|c|}{$\mathrm{IC}_{50}$ for cholesteryl ester (CE) synthesis $(\mu \mathrm{M})$} \\
\hline & \multicolumn{3}{|c|}{ Cell-based assay } & \multicolumn{3}{|c|}{ Enzyme assay } \\
\hline & ACAT1-CHO & ACAT2-CHO & $\mathrm{SI}^{*}$ & ACAT1 & ACAT2 & $\mathrm{SI}^{*}$ \\
\hline Pyripyropene A & $>80$ & 0.07 & $>1,000$ & $>30$ & 0.06 & $>500$ \\
\hline Pyripyropene B & 48 & 2.0 & 24.0 & 30 & 0.8 & 37.5 \\
\hline Pyripyropene C & 32 & 0.36 & 88.9 & 15 & 0.35 & 42.9 \\
\hline Pyripyropene D & 38 & 1.5 & 25.3 & 15 & 1.2 & 12.5 \\
\hline Purpactin A & 2.5 & 1.5 & 1.7 & 0.9 & 1.8 & 2.0 \\
\hline Purpactin B & 10 & 5.7 & 1.8 & 22 & 12 & 1.8 \\
\hline Purpactin C & 10 & 10 & 1.0 & 28 & 30 & 1.1 \\
\hline Glisoprenin A & 4.3 & 10 & 2.3 & 0.4 & 1.3 & 3.3 \\
\hline Terpendole C & 10 & 10 & 1.0 & 8.0 & 0.5 & 16.0 \\
\hline Beauvericin & 2.0 & 0.7 & 2.9 & 0.35 & 0.35 & 1.0 \\
\hline Beauveriolide I & 0.6 & 20 & 33.3 & 2.2 & 1.9 & 1.2 \\
\hline Beauveriolide III & 0.9 & $>20$ & $>22.2$ & 3.0 & 3.0 & 1.0 \\
\hline Phenochalasin A & $>20$ & $>20$ & - & $>100$ & $>100$ & - \\
\hline Spylidone & 25 & 5.0 & 5.0 & 7.0 & 3.0 & 2.3 \\
\hline Sespendole & 12 & 6.5 & 1.8 & 20 & 12 & 1.7 \\
\hline K97-0239A & 9.0 & $>13$ & - & 40 & 38 & 1.1 \\
\hline K97-0239B & $>13$ & $>13$ & - & $>70$ & $>70$ & - \\
\hline CL-283,546 & 0.1 & 0.09 & 1.1 & 0.12 & 0.06 & 2.0 \\
\hline
\end{tabular}

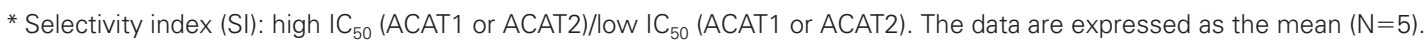

inhibit both ACAT isozymes to similar extents in the enzyme assay although they showed selective inhibition against ACAT1 (SI, 33 and >22) in the cell-based assay.

\section{Discussion}

As summarized in Figs. 1 and 2, our research group previously discovered a number of compounds which inhibited ACAT activity in rat liver microsomes (which mainly express ACAT2) and lipid droplet accumulation in intact macrophages (which express ACAT1) [37]. The compounds were (re-)evaluated in the several assay systems for CE synthesis as described in this study: lipid droplet accumulation in mouse macrophages, CE synthesis in ACAT1- and ACAT2-CHO cells and ACAT activity in microsomes prepared from ACAT1- and ACAT2-CHO cells.

The purposes of this study were as follows; 1) ACAT has been recognized as a potential target for the development of antiatherosclerotic agents, and a number of ACAT inhibitors have been reported. Recent studies of ACAT revealed that there are two isozymes, ACAT1 and ACAT2, with different functions in human body [3 7]. However, the selectivity of microbial ACAT inhibitors toward ACAT1 and ACAT2 is only partially understood. Therefore, we aimed to assess their selectivity toward these isozymes. Microbial ACAT inhibitors (Fig. 1) were expected to inhibit at least ACAT2 because they were isolated based on the inhibition of ACAT activity in rat liver microsomes. Additionally, we tested whether these microbial ACAT inhibitors inhibited lipid droplet accumulation in mouse macrophages (via a process involving ACAT1). 2) The molecular targets of the microbial compounds (Fig. 2) discovered as inhibiting lipid droplet accumulation in macrophages were unknown. However, it was worthy testing whether they inhibit ACAT activity as one of the potential targets.

In this study, pyripyropene A was reconfirmed to be an ACAT2-selective inhibitor with the highest SI value $(>1,000)$ among the agents studied $[9,36]$. Accordingly, it is not surprising that it showed no effect on lipid droplet accumulation in macrophages (Table 1). Interestingly, pyripyropenes $\mathrm{B}, \mathrm{C}$ and $\mathrm{D}$, having only a subtle difference in acyl chains from pyripyropene A (Fig. 1), inhibited ACAT1 activity, resulting in much lower SI values (24 to 
89) than that of pyripyropene A (Table 2).

Purpactins, glisoprenin A and terpendole $\mathrm{C}$ were found to inhibit both ACAT1 and ACAT2 to similar extents (SI, 1.0 to 2.3). Therefore, they inhibited lipid droplet accumulation in macrophages by selective blockage of $\mathrm{CE}$ synthesis catalyzed by ACAT1. However, beauvericin inhibited not only $\mathrm{CE}$ but also TG synthesis in macrophages although it inhibited ACAT1 and ACAT2, which can be explained by the fact that beauvericin has several molecular targets in eucaryotic cells such as ionophore activity, nonselective enzyme inhibition, etc. [38 40] and shows toxic effects on macrophages [31].

Among the inhibitors of lipid droplet accumulation in macrophages (Fig. 2), beauveriolides I and III, expected to provide leads for the development of a new type of antiatherosclerotic agent $[31,32]$, were found to inhibit ACAT1 rather selectively (SI, 33 and $>22$, respectively) (Table 2) in the cell-based assays. Interestingly, ACAT assays using microsomes indicated that beauveriolides inhibited both isozymes almost equally (SI, 1.2 and 1.0), in accord with those in mouse liver and macrophage microsomes as previously reported [31]. Current research activities regarding ACAT is limited to cell biology and biochemistry due to the fact that the crystal structure of ACAT has not yet been determined as a result of difficulties associated with purification of this protein. ACAT1 and ACAT2 share extensive homology near their $C$ termini, but not near their $N$ termini [4]. Although the enzymological properties of ACAT isozymes are also very similar [41], the exact membrane topology and the active site of ACAT isozymes remain unresolved. Joyce et al. reported that the active site of ACAT1 $\left(\mathrm{Ser}_{269}\right)$ is located in the cytoplasm, while that of ACAT2 $\left(\mathrm{Ser}_{249}\right)$ is located in the lumen [42]. On the other hand, Chang et al. reported that the active site of ACAT1 $\left(\mathrm{His}_{460}\right)$ and ACAT2 $\left(\mathrm{His}_{434}\right)$ is located in the transmembrane domain $[43,44]$. The different effects of beauveriolides on the ACAT isozymes between the cellbased assay and enzyme assay might be due to the different distributions of the active sites of two ACAT isozymes in the ER, but this remains to be proven. Thus, pyripyropene A and beauveriolides are expected to not only provide leads for drug development but also useful probes to study the function of the ACAT isozymes.

The present findings made it clear that ACAT is not the molecular target of phenochalasin A and K97-0239s, because they showed no or very weak inhibition of ACAT1 and ACAT2. We also concluded that the molecular targets of spylidone could be ACAT1 and ACAT2. Sespendole also inhibited ACAT1 and ACAT2, but this compound also has a different target because it inhibited not only CE but TG synthesis in macrophages.
Acknowledgments This work was supported by grant-in-aid for Scientific Research on Priority Areas 16073215, Scientific Research (B) 18390008 and the 21st Century COE Program from the Ministry of Education, Culture, Sports, Science and Technology, Japan, and by the Hoh-ansha Foundation, Japan. T.O. is supported by a Research Fellowship of the Japan Society for the Promotion of Science for Young Scientists.

\section{References}

1. Roth BD. ACAT inhibitors: Evolution from cholesterolabsorption inhibitors to antiatherosclerotic agents. Drug Disc Today 3: 19-25 (1998)

2. Alegret M, Llaverias, G, Silvestre JS. Acyl-coenzyme A : cholesterol acyltransferase inhibitors as hypolipidemic and antiatherosclerotic agents. Methods Find Clin Pharmacol 26: 563-586 (2004)

3. Chang CC, Huh HY, Cadigan KM, Chang TY. Molecular cloning and functional expression of human acyl-coenzyme A : cholesterol acyltransferase cDNA in mutant Chinese hamster ovary cells. J Biol Chem 268: 20747-20755 (1993)

4. Anderson RA, Joyce C, Davis M, Reagan JW, Clark M, Shelness GS, Rudel LL. Identification of a form of acylCoA: cholesterol acyltransferase specific to liver and intestine in nonhuman primates. J Biol Chem 273: 26747-26754 (1998)

5. Cases S, Novak S, Zheng YW, Myers HM, Lear SR, Sande E, Welch CB, Lusis AJ, Spencer TA, Krause BR, Erickson SK, Farese RV Jr. ACAT-2, a second mammalian acylCoA : cholesterol acyltransferase. Its cloning, expression, and characterization. J Biol Chem 273: 26755-26764 (1998)

6. Oelkers P, Behari A, Cromley D, Billheimer JT, Sturley SL. Characterization of two human genes encoding acyl coenzyme A : cholesterol acyltransferase-related enzymes. J Biol Chem 273: 26765-26771 (1998)

7. Parini P, Davis M, Lada AT, Erickson SK, Wright TL, Gustafsson U, Sahlin S, Einarsson C, Eriksson M, Angelin B, Tomoda H, Ōmura S, Willingham MC, Rudel LL. ACAT2 is localized to hepatocytes and is the major cholesterol-esterifying enzyme in human liver. Circulation 110: 2017-2023 (2004)

8. Giovannoni MP, Piaz VD, Vergelli C, Barlocco D. Selective ACAT inhibitors as promising antihyperlipidemic, antiathero-sclerotic and anti-Alzheimer drugs. Mini Rev Med Chem 3: 576-584 (2003)

9. Lada AT, Davis M, Kent C, Chapman J, Tomoda H, Ōmura S, Rudel LL. Identification of ACAT1- and ACAT2-specific inhibitors using a novel, cell-based fluorescence assay: individual ACAT uniqueness. J Lipid Res 45: 378-386 (2004)

10. Ikenoya M, Yoshinaka Y, Kobayashi H, Kawamine K, Shibuya K, Sato F, Sawanobori K, Watanabe T, Miyazaki A. A selective ACAT-1 inhibitor, K-604, suppresses fatty streak lesions in fat-fed hamsters without affecting plasma 
cholesterol levels. Atherosclerosis: in press (2006)

11. Ōmura S, Tomoda H, Kim YK, Nishida H, Pyripyropenes highly potent inhibitors of acyl-CoA:cholesterol acyltransferase produced by Aspergillus fumigatus. J Antibiot 46: 1168-1169 (1993)

12. Tomoda H, Kim YK, Nishida H, Masuma R, Ōmura S. Pyripyropenes, novel inhibitors of acyl-CoA : cholesterol acyltransferase produced by Aspergillus fumigatus. I. Production, isolation, and biological properties. J Antibiot 47: 148-153 (1994)

13. Kim YK, Tomoda H, Nishida H, Sunazuka T, Obata R, Ōmura S. Pyripyropenes, novel inhibitors of acyl-CoA: cholesterol acyltransferase produced by Aspergillus fumigatus. II. Structure elucidation of pyripyropenes A, B, C and D. J Antibiot 47: 154-162 (1994)

14. Tomoda H, Nishida H, Masuma R, Cao J, Okuda S, Ōmura S. Purpactins, new inhibitors of acyl-CoA: cholesterol acyltransferase produced by Penicillium purpurogenum. I. Production, isolation and physico-chemical and biological properties. J Antibiot 44: 136-143 (1991)

15. Nishida H, Tomoda $\mathrm{H}$, Cao J, Okuda S, Ōmura S. Purpactins, new inhibitors of acyl-CoA:cholesterol acyltransferase produced by Penicillium purpurogenum. II. Structure elucidation of purpactins A, B and C. J Antibiot 44: 144-151 (1991)

16. Tomoda H, Huang XH, Nishida H, Masuma R, Kim YK, Ōmura S. Glisoprenins, new inhibitors of acylCoA : cholesterol acyltransferase produced by Gliocladium sp. FO-1513. I. Production, isolation and physico-chemical and biological properties. J Antibiot 45: 1202-1206 (1992)

17. Nishida H, Huang XH, Tomoda H, Ōmura S. Glisoprenins, new inhibitors of acyl-CoA: cholesterol acyltransferase produced by Gliocladium sp. FO-1513. II. Structure elucidation of glisoprenins A and B. J Antibiot 45: 1669-1676 (1992)

18. Ghosh I, Kishi Y, Tomoda H, Ōmura S. Guse of achiral praseodymium shift reagent in predicting the complete stereostructure of glisoprenin A. Org Lett 6: 4719-4722 (2004)

19. Huang XH, Tomoda H, Nishida H, Masuma R, Ōmura S. Terpendoles, novel ACAT inhibitors produced by Albophoma yamanashiensis. I. Production, isolation and biological properties. J Antibiot 48: 1-4 (1995)

20. Huang XH, Nishida H, Tomoda H, Tabata N, Shiomi K, Yang DJ, Takayanagi H, Ōmura S. Terpendoles, novel ACAT inhibitors produced by Albophoma yamanashiensis. II. Structure elucidation of terpendoles A, B, C and D. J Antibiot 48: 5-11 (1995)

21. Tomoda H, Tabata N, Yang DJ, Takayanagi H, Ōmura S. Terpendoles, novel ACAT inhibitors produced by Albophoma yamanashiensis. III. Production, isolation and structure elucidation of new components. J Antibiot 48: 793-804 (1995)

22. Namatame I, Tomoda H, Si S, Yamaguchi Y, Masuma R, Ōmura S. Beauveriolides, specific inhibitors of lipid droplet formation in mouse macrophages, produced by Beauveria sp. FO-6979. J Antibiot 52: 1-6 (1999)

23. Namatame I, Tomoda H, Tabata N, Si S, Ōmura S. Structure elucidation of fungal beauveriolide III, a novel inhibitor of lipid droplet formation in mouse macrophages. J Antibiot 52: 7-12 (1999)

24. Matsuda D, Namatame I, Tomoda H, Kobayashi S, Zocher R, Kleinkauf H, Ōmura S. New beauveriolide produced by amino acid-supplemented fermentation of Beauveria sp. FO-6979. J Antibiot 57: 1-9 (2004)

25. Mochizuki K, Ohmori K, Tamura H, Shizuri H, Nishiyama $\mathrm{S}$, Miyoshi E, Yamamura S. The structures of bioactive cyclodepsipeptides, beauveriolides I and II, metabolites of entomopathogenic fungi Beauveria sp. Bull Chem Soc Jpn 66: 3041-3046 (1993)

26. Tomoda H, Namatame I, Si S, Kawaguchi K, Masuma R, Namikoshi M, Ōmura S. Phenochalasins, inhibitors of lipid droplet formation in mouse macrophages, produced by Phomopsis sp. FT-0211. J Antibiot 52: 851-856 (1999)

27. Tomoda H, Namatame I, Tabata N, Kawaguchi K, Si S, Ōmura S. Structure elucidation of fungal phenochalasins, novel inhibitors of lipid droplet formation in mouse macrophages. J Antibiot 52: 857-861 (1999)

28. Koyama N, Nagahiro T, Yamaguchi Y, Ohshiro T, Masuma R, Tomoda H, Ōmura S. Spylidone, a novel inhibitor of lipid droplet accumulation in mouse macrophages produced by Phoma sp. FKI-1840. J Antibiot 58: 338-345 (2005)

29. Uchida R, Kim YP, Namatame I, Tomoda H, Ōmura S. Sespendole, a new inhibitor of lipid droplet synthesis in macrophages, produced by Pseudobotrytis terrestris FKA25. J Antibiot 59: 93-97 (2006)

30. Namatame I, Tomoda H, Matsuda D, Tabata N, Kobayashi S, Ōmura S. K97-0239A and B, new inhibitors of macrophage foam cell formation, produced by Streptomyces sp. K970239. Proc Japan Acad 78 (Ser. B): 45-50 (2002)

31. Namatame I, Tomoda H, Ishibashi S, Ōmura S. Antiatherogenic activity of fungal beauveriolides, inhibitors of lipid droplet accumulation in macrophages. Proc Natl Acad Sci USA 101: 737-742 (2004)

32. Chem Eng News 18: 15 (2004)

33. Namatame I, Tomoda H, Arai H, Inoue K, Ōmura S. Complete inhibition of mouse macrophage-derived foam cell formation by triacsin C. J Biochem 25: 319-327 (1999)

34. Bligh EG, Dyer W. A rapid method of total lipid extraction and purification. Can J Biochem Physiol 37: 911-917 (1959)

35. Field FJ, Cooper AD, Erickson SK. Regulation of rabbit intestinal acyl coenzyme A-cholesterol acyltransferase in vivo and in vitro. Gastroenterology 83: 873-880 (1982)

36. Cho KH, An S, Lee WS, Paik YK, Kim YK, Jeong TS. Mass-production of human ACAT-1 and ACAT-2 to screen isoform-specific inhibitor: a different substrate specificity and inhibitory regulation. Biochem Biophys Res Commun 309: 864-872 (2003)

37. Tomoda H, Namatame I, Ōmura S. Microbial metabolites with inhibitory activity against lipid metabolism. Proc Japan 
Acad 78 (Ser. B): 217-240 (2002)

38. Kouri K, Lemmens M, Gruber RL. Beauvericin-induced channenls in ventricular myocytes and liposomes. Biochim Biophys Acta 1609: 203-210 (2003)

39. Jow GM, Chou CJ, Chen BF, Tsai JH. Beauvericin induces cytotoxic effects in human acute lympoblastic leukemia cells through cytochrome c release, caspase 3 activation: the causative role of calcium. Cancer Lett 216: 165-173 (2004)

40. Fukuda T, Arai M, Yamaguchi Y, Masuma R, Tomoda H, Ōmura S. New beauvericins, potentiators of antifungal miconazole activity, produced by Beauveria sp. FKI-1366. I. Taxonomy, fermentation, isolation and biological properties, J Antibiot 57: 110-116 (2004)

41. Lin S, Cheng D, Liu MS, Chen J, Chang TY. Human acylCoA : cholesterol acyltransferase-1 in the endoplasmic reticulum contains seven transmembarane domains. J Biol
Chem 274: 23276-23285 (1999)

42. Joyce CW, Shelness GS, Davis MA, Lee RG, Skinner K, Anderson RA, Rudel LL. ACAT1 and ACAT2 membrane topology segregates a serine residue essential for activity to opposite sides of the endoplasmic reticulum membrane. Mol Biol Cell 11: 3675-3687 (2000)

43. Guo ZY, Lin S, Heinen JA, Chang CC, Chang TY. The active site His-460 of Human acyl-coenzyme A : cholesterol acyltransferase 1 resides in a hitherto undisclosed transmembrane domain. J Biol Chem 280: 37814-37826 (2005)

44. Lin S, Lu X, Chang CC, Chang TY. Human acyl-coenzyme A : cholesterol acyltransferase expressed in Chinese hamuster ovary cells: Membrane topology and active site location. Mol Biol Cell 14: 2447-2460 (2003) 